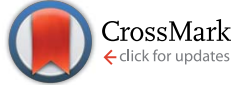

Cite this: RSC Adv., 2015, 5, 39870

Received 4th February 2015

Accepted 27th April 2015

DOI: $10.1039 / \mathrm{c} 5 \mathrm{ra02203g}$

www.rsc.org/advances

\section{Structure, absolute configuration, and conformational study of resorcylic acid derivatives and related congeners from the fungus Penicillium brocae $\dagger$}

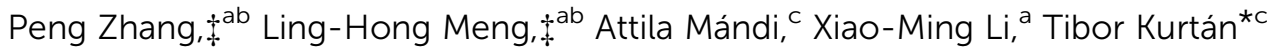 \\ and Bin-Gui Wang*a
}

In addition to three known resorcylic acid derivatives of the $(14 R)$ series (1-3), six new compounds including one new resorcylic acid derivative (13-hydroxydihydroresorcylide, 4) and five new loop-opened resorcylic acid-related congeners including brocapyrone A (5) and brocaketones A-D (6-9), were isolated and identified from the culture extract of a marine mangrove-derived endophytic fungus Penicillium brocae MA-192. Conformational analysis and TDDFT-ECD calculations of 1, 3, and 4 were carried out to confirm the $(14 R)$ absolute configuration and identify the solution conformers and factors that govern the correlation between stereochemistry and signs of the characteristic ECD bands. The single crystal X-ray of 3 and 5 allowed applying the solid-state TDDFT-ECD approach for 3 to compare the structures of solution and solid-state conformers and correlate the $n-\pi^{*} E C D$ transition of 5 with the helicity and absolute configuration of the dihydroisocoumarin moiety. All compounds were evaluated for antioxidant activity against DPPH and ABTS radicals.

\section{Introduction}

Reactive oxygen species (ROS) are harmful intermediates produced by biological combustion involved in life processes. The excess of ROS in the body could damage DNA and other biomolecules such as lipids, proteins, and enzymes, leading to cell and/or tissue injury correlated with various diseases such as aging, apoplexia, carcinogenesis, diabetes and inflammation. ${ }^{1-4}$ Antioxidants, which donate hydrogen atoms to free radicals and convert them to nonradical products, ${ }^{1}$ are effective agents to protect the body against oxidative stress caused by ROS. Phenolic and polyphenolic derivatives represent the main family of electron/proton-donating antioxidants. ${ }^{5}$ Due to the potential health risks of synthetic antioxidants such as

${ }^{a}$ Key Laboratory of Experimental Marine Biology, Institute of Oceanology, Chinese Academy of Sciences, Nanhai Road 7, Qingdao 266071, P. R. China. E-mail: wangbg@ms.qdio.ac.cn

${ }^{b}$ University of Chinese Academy of Sciences, Yuquan Road 19A, Beijing 100049, P. R. China

${ }^{c}$ Department of Organic Chemistry, University of Debrecen, РОВ 20, 4010 Debrecen, Hungary. E-mail: kurtan.tibor@science.unideb.hu; Web: http://szerves.science. unideb.hu/eng/html/kurtan_tibor.html

$\dagger$ Electronic supplementary information (ESI) available: The conformational analysis, solution ECD and computed ECD spectra of compounds 1, 3, and 4, selected 1D and 2D NMR spectra of compounds 4-9. CCDC 916585. For ESI and crystallographic data in CIF or other electronic format see DOI: 10.1039/c5ra02203g

† P. Z. and L. H. M. contributed equally to this work. butylated hydroxyanisole (BHA) and butylated hydroxytoluene (BHT), there is an increasing interest in searching for naturally occurring antioxidants in recent years. ${ }^{6}$ Natural antioxidants do not only exert radical scavenging activity, reducing oxidative stress, and protecting against oxidative damage, but also provide an indirect protection by activating endogenous antioxidant defense systems. ${ }^{7}$ Numerous naturally-occurring antioxidants have been characterized from various resources such as edible mushrooms, ${ }^{3,8}$ eggplants, ${ }^{9}$ brown algae, ${ }^{10}$ bamboos $^{11}$ and actinomycetes. ${ }^{12}$ These antioxidants can be formulated to prevent oxidative damage in the human body by providing nutraceuticals.

In the recent two decades, marine-derived fungi have been proved to be a productive source of secondary metabolites with novel structures and diverse bioactivities. ${ }^{13}$ In connection with our ongoing search for bioactive metabolites from marinederived fungi, ${ }^{14-17}$ Penicillium brocae MA-192, an endophytic fungus isolated from the fresh leaves of marine mangrove plant Avicennia marina, attracted our attention. ${ }^{18}$ The extract of this fungus showed antioxidant activity against DPPH and ABTS radicals in the original assays, with $\mathrm{IC}_{50}$ values of 72.4 and $80.6 \mu \mathrm{g} \mathrm{mL} \mathrm{m}^{-1}$, respectively. Preliminary chemical study on this fungus has resulted in the isolation and identification of three new alkaloids (brocaeloids A-C). ${ }^{18}$ Further work on the remaining fractions has now resulted in the isolation of six new resorcylic acid derivatives including a twelve-membered resorcylic acid lactone $\left(\mathrm{RAL}_{12}\right), 13$-hydroxydihydroresorcylide (4), and 
five new loop-opened derivatives including brocapyrone A (5) and brocaketones A-D (6-9), together with the (14R) steroisomers of three known $\mathrm{RAL}_{12}$ derivatives, dihydroresorcylide (1), cis-resorcylide (2), and 10-hydroxydihydroresorcylide (3). The meta-dihydroxybenzene moiety is a common structural motif in these compounds (1-9). This paper describes the isolation, structural elucidation, and radical scavenger activity of compounds 1-9.

\section{Results and discussion}

The culture extract of $P$. brocae MA-192 was purified by a combination of column chromatography with silica gel, Sephadex LH-20, Lobar LiChroprep RP-18, and semi-preparative HPLC, to yield six new polyketides including 13-hydroxydihydroresorcylide (4), brocapyrone A (5), and brocaketones A-D (6-9), together with three recently reported RAL derivatives $(\mathbf{1 - 3})^{\mathbf{1 9}}$ (Fig. 1). The planar structures of these RALs were identified as dihydroresorcylide (1), cis-resorcylide (2), and 10-hydroxydihydroresorcylide (3) by comparing the physicochemical and spectroscopic data with those previously reported..$^{\mathbf{2 0 2 1}}$ The absolute configuration at C-14 of these RALs had been previously assumed to be $(14 S)$ on the basis of biosynthetic considerations $^{20,21}$ but the enantioselective synthesis of $(S)$-dihydroresorcylide ${ }^{22}$ and comparison of the specific rotations revised the absolute configuration as $(14 R)$. Very recently, the isolation of 1-3 belonging to the (14R) series has been reported from the heterologous production in Saccharomyces cerevisiae. ${ }^{19}$ Electronic circular dichroism (ECD) supported by TDDFT-ECD calculations has been proved an efficient tool for the configurational assignment of conformationally flexible<smiles>[R][C@H](C)[C@@H](C)OC(=O)c1c(O)cc(O)cc1CC(=O)CCCCC</smiles>
$4 \mathrm{R}=\mathrm{OH}(13 S)$<smiles>C[C@H]1CCC[C@@H](O)CC(=O)Cc2cc(O)cc(O)c2C(=O)O1</smiles>
3

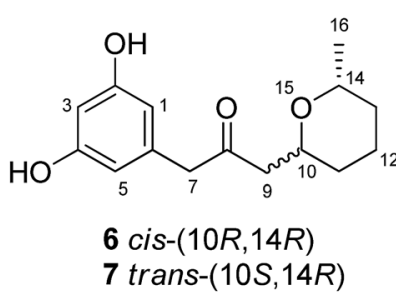<smiles>C[C@@H]1CCC/C=C\C(=O)Cc2cc(O)cc(O)c2C(=O)O1</smiles>

2

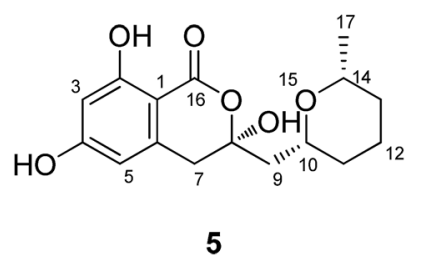

5

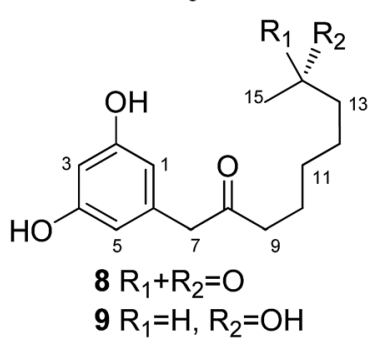

Fig. 1 Structures of the isolated compounds 1-9. benzenediol lactones (BDLs), which also reveals the geometry of the preferred solution conformers. ${ }^{23-25}$

In order to test the applicability of the solution TDDFT-ECD calculation approach on flexible RAL derivatives and explore the correlation between the stereochemistry and the characteristic ECD transitions, the solution conformers and ECD spectra of 1 and 3 were thus computed (SI-1, see ESI $\dagger$ ). Because compound 2 has only one stereogenic centre, the absolute configuration determination of $\mathbf{2}$ was thus relatively straightforward according to its optical rotation. The identification of solution conformers of RAL derivatives has been recently attracted considerable attention due to their potent protein kinase inhibitory activity. ${ }^{26}$ This approach allowed determining the absolute configurations as $(14 R)$ for 1 and $(10 R, 14 R)$ for 3 . Moreover, the solid-state geometry of 3 could be deduced by $\mathrm{X}$-ray diffraction analysis, which allowed applying the solidstate TDDFT-ECD approach for 3 to compare the structures of solution and solid-state conformers (SI-2, see ESI $\dagger$ ). The results of the solid-state TDDFT-ECD calculation for $\mathbf{3}$ confirmed independently the $(10 R, 14 R)$ absolute configuration, which is in accordance with those of the solution TDDFT-ECD calculation.

Compound 4 was obtained as white amorphous powder, with the molecular formula $\mathrm{C}_{16} \mathrm{H}_{20} \mathrm{O}_{6}$, as determined by the HRESIMS data. The ${ }^{1} \mathrm{H}$ NMR spectrum (Table 1) showed the presence of one secondary methyl group $\left(\delta_{\mathrm{H}} 1.24, \mathrm{H}-17\right)$, five methylenes $\left(\delta_{\mathrm{H}}\right.$ 1.31-4.35, $\mathrm{H}-7$ and $\mathrm{H}-9$ to $\left.\mathrm{H}-12\right)$, two oxygenated methines $\left(\delta_{\mathrm{H}} 3.41, \mathrm{H}-13\right.$ and $\left.\delta_{\mathrm{H}} 4.52, \mathrm{H}-14\right)$, and two aromatic protons $\left(\delta_{\mathrm{H}} 6.05, \mathrm{H}-5\right.$ and $\left.\delta_{\mathrm{H}} 6.15, \mathrm{H}-3\right)$, indicating a typical pattern of meta-coupling $(J=1.9 \mathrm{~Hz})$ that consistent with a 1,2,3,5-tetrasubstituted phenyl moiety. The ${ }^{13} \mathrm{C}$ NMR spectroscopic data (Table 2) exhibited the presence of 16 carbons, which were further classified by DEPT experiments into one methyl, five methylenes, four methines (with two aromatic and two oxygenated), four quaternary aromatic carbons, one ester carbonyl, and one ketocarbonyl carbons. The ${ }^{1} \mathrm{H}-$ and ${ }^{13} \mathrm{C}-\mathrm{NMR}$ data resembled those of 10-hydroxydihydroresorcylide (3). ${ }^{19}$ However, compound 4 differed from 3 in the position of the hydroxy group (C-10 in 3 and C-13 in 4). The HMBC correlations from $\mathrm{H}-17$ to the oxymethine carbons $\mathrm{C}-13$ and $\mathrm{C}-14$ placed the $\mathrm{OH}$ group at $\mathrm{C}-13$, which was supported by COSY correlations from $\mathrm{H}-14$ to $\mathrm{H}-13$ and $\mathrm{H}-17$ (Fig. 2). The relative configuration of C-13 and C-14 was determined as trans- $\left(13 S^{*}, 14 R^{*}\right)$ on the basis of the large ${ }^{3} J_{13-\mathrm{H}, 14-\mathrm{H}}$ coupling constant $(9.0 \mathrm{~Hz})$ and the NOE correlation between $\mathrm{H}-17$ and $\mathrm{H}-13$. Accordingly, the planar structure of compound $\mathbf{4}$ was determined and it was named as 13-hydroxydihydro-resorcylide.

The absolute configuration of compound 4 was established by DFT conformational analysis and TDDFT-ECD calculations. The initial MMFF conformational search on the arbitrarily chosen $(13 S, 14 R)-4$ resulted in 189 conformers, which were reoptimized at both $\mathrm{B} 3 \mathrm{LYP} / 6-31 \mathrm{G}(\mathrm{d})$ level in vacuo and $\mathrm{B} 97 \mathrm{D} /$ TZVP level with PCM solvent model for MeCN. The B3LYP/ 6-31G(d) in vacuo reoptimization afforded two conformers above $2 \%$ population with the $13-\mathrm{OH}_{\mathrm{ax}}, 14-\mathrm{Me}_{\mathrm{ax}}$ conformer as the major one (conf. $\mathrm{A}, 91 \%$ ) and the $13-\mathrm{OH}_{\mathrm{eq}}, 14-\mathrm{Me}_{\mathrm{eq}}$ conformer as the minor (conf. B, 3.6\%) (Fig. 3). 
Table $1{ }^{1} \mathrm{H}$ NMR data for compounds 4-9 (500 MHz, J in Hz)

\begin{tabular}{|c|c|c|c|c|c|c|}
\hline Position & $4^{a}$ & $5^{a}$ & $6^{b}$ & $7^{c}$ & $\mathbf{8}^{b}$ & $9^{a}$ \\
\hline 1 & & & 6.15, br s & $6.22, \mathrm{~d}(1.9)$ & 6.26, br s & $6.02, \mathrm{~d}(1.9)$ \\
\hline 3 & $6.15, \mathrm{~d}(1.9)$ & 6.11, br s & 6.20, br s & $6.25, \mathrm{~d}(1.9)$ & 6.28, br s & $6.06, \mathrm{~d}(1.9)$ \\
\hline 5 & $6.05, \mathrm{~d}(1.9)$ & 6.05 , br s & 6.15 , br s & $6.22, \mathrm{~d}(1.9)$ & 6.26 , br s & $6.02, \mathrm{~d}(1.9)$ \\
\hline 7 & $\begin{array}{l}4.35, \mathrm{~d}(18.3) \\
3.71, \mathrm{~d}(18.3)\end{array}$ & 3.66, br s & $3.59, \mathrm{~s}$ & $3.56, \mathrm{~s}$ & $3.55, \mathrm{~s}$ & $3.46, \mathrm{~s}$ \\
\hline 9 & $\begin{array}{l}2.63, \text { dd }(14.3,9.2) \\
2.25, \text { dd }(14.3,9.2)\end{array}$ & $2.34, \mathrm{~m}$ & $\begin{array}{l}2.79, \text { dd }(16.3,7.8) \\
2.48, \text { dd }(16.3,4.4)\end{array}$ & $\begin{array}{l}2.77, \text { dd }(15.5,7.8) \\
2.54, \text { dd }(15.5,5.9)\end{array}$ & $2.47, \mathrm{t}(7.0)$ & $2.39, \mathrm{t}(7.3)$ \\
\hline 10 & $\begin{array}{l}1.80, \mathrm{~m} \\
1.72, \mathrm{~m}\end{array}$ & $3.38, \mathrm{~m}$ & $3.87, \mathrm{~m}$ & $4.22, \mathrm{~m}$ & $1.54, \mathrm{~m}$ & $1.39, \mathrm{~m}$ \\
\hline 11 & $1.38, \mathrm{~m}$ & $\begin{array}{l}1.52, \mathrm{~m} \\
1.10, \mathrm{~m}\end{array}$ & $\begin{array}{l}1.56, \mathrm{~m} \\
1.16, \mathrm{~m}\end{array}$ & $\begin{array}{l}1.27, \mathrm{~m} \\
1.22, \mathrm{~m}\end{array}$ & $1.23, \mathrm{~m}$ & $1.15, \mathrm{~m}$ \\
\hline 12 & $\begin{array}{l}1.47, \mathrm{~m} \\
1.31, \mathrm{~m}\end{array}$ & $\begin{array}{l}1.71, \mathrm{~m} \\
1.48, \mathrm{~m}\end{array}$ & $\begin{array}{l}1.79, \mathrm{~m} \\
1.57, \mathrm{~m}\end{array}$ & $1.60, \mathrm{~m}$ & $1.54, \mathrm{~m}$ & $1.21, \mathrm{~m}$ \\
\hline 13 & 3.41, dd $(9.0,7.5)$ & $\begin{array}{l}1.55, \mathrm{~m} \\
1.14, \mathrm{~m}\end{array}$ & $\begin{array}{l}1.56, \mathrm{~m} \\
1.19, \mathrm{~m}\end{array}$ & $1.60, \mathrm{~m}$ & $2.42, \mathrm{t}(7.0)$ & $1.26, \mathrm{~m}$ \\
\hline 14 & $4.52, \mathrm{dq}(9.0,6.1)$ & $3.66, \mathrm{~m}$ & $3.59, \mathrm{~m}$ & $3.80, \mathrm{~m}$ & & $3.52, \mathrm{~m}$ \\
\hline 15 & & & & & $2.15, \mathrm{~s}$ & $0.99, \mathrm{~d}(6.1)$ \\
\hline 16 & & & $1.14, \mathrm{~d}(6.1)$ & $1.09, \mathrm{~d}(6.5)$ & & \\
\hline 17 & $1.24, \mathrm{~d}(6.1)$ & $1.05, \mathrm{~d}(5.9)$ & & & & \\
\hline $2-\mathrm{OH}$ & 11.08, br s & & & & & \\
\hline $14-\mathrm{OH}$ & & & & & & $4.26, \mathrm{~d}(4.6)$ \\
\hline
\end{tabular}

In the major in vacuo $13-\mathrm{OH}_{\mathrm{ax}}, 14-\mathrm{Me}_{\mathrm{ax}}$ conformer, the axial 13-OH group was hydrogen-bonded to the C-8 carbonyl group, which presumably compensated the unfavourable trans-diaxial arrangement of the 13-OH and 14-Me groups. The measured large ${ }^{3} J_{13-\mathrm{H}, 14-\mathrm{H}}$ coupling constant $(9.0 \mathrm{~Hz})$ must have derived from the $13-\mathrm{OH}_{\mathrm{eq}}, 14-\mathrm{Me}_{\mathrm{eq}}$ conformer, in which $13-\mathrm{H}$ and $14-\mathrm{H}$ are trans-diaxial and there is no intramolecular hydrogen bonding between the 13-OH and the C-8 carbonyl oxygen. The NMR data recorded in DMSO- $d_{6}$ suggested that this conformer was the dominant one in DMSO- $d_{6}$, which could be attributed to the effect of the strongly coordinating solvent breaking hydrogen bonding interactions. The solution ECD spectrum of $\mathbf{4}$ in acetonitrile was found very similar to that of 1 . The Boltzmann-weighted ECD spectra of the B3LYP/6-31G(d) in vacuo conformers of $(13 S, 14 R)-4$ (Fig. 4) reproduced well the high-energy ECD bands of the experimental curve allowing the determination of the absolute configuration as $(13 S, 14 R)$. The low-energy negative $\mathrm{CE}$ at $306 \mathrm{~nm}$ was missing from the computed ECD spectrum, since it derived from the $13-\mathrm{OH}_{\mathrm{eq}}, 14-\mathrm{Me}_{\mathrm{eq}}$ conformer, the population of which is highly underestimated by this method.

Table $2{ }^{13} \mathrm{C}$ NMR data for compounds 4-9 (125 MHz)

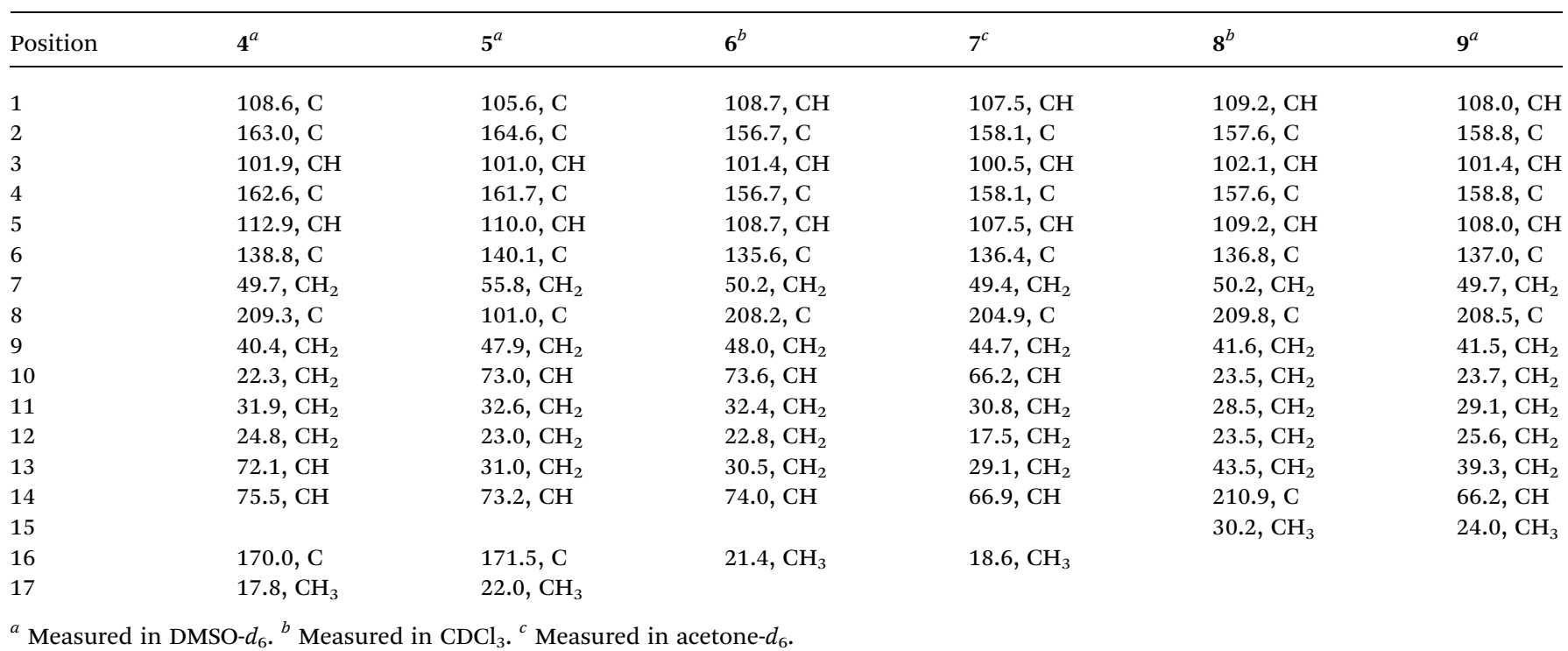



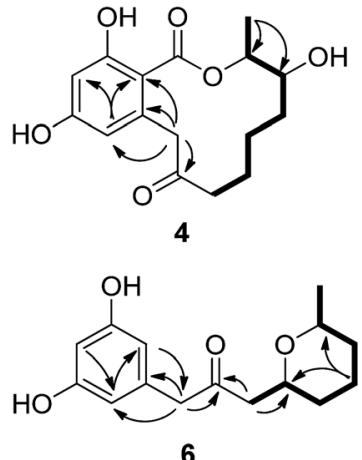

6

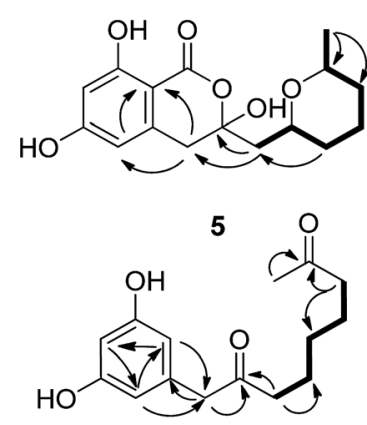

8
Fig. 2 Key HMBC (arrows) and COSY (bold lines) correlations of compounds $4-6$ and 8.

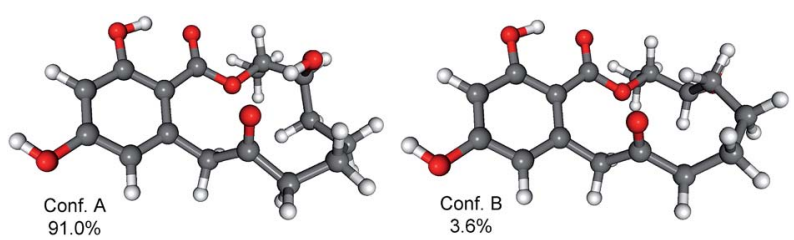

Fig. 3 Structure and population of the low-energy B3LYP/6-31G(d) conformers $(>2 \%)$ of $(13 S, 14 R)-4$.

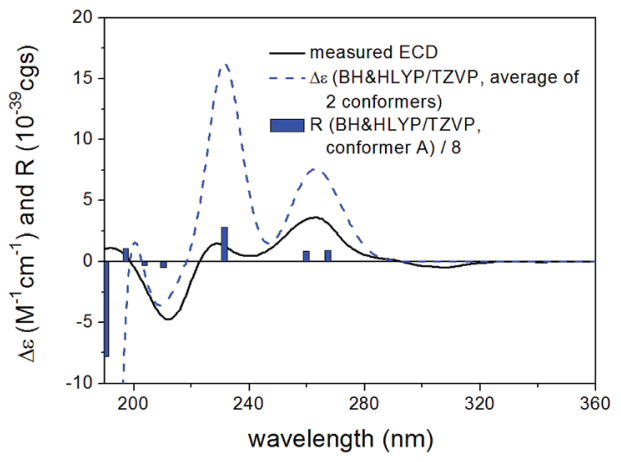

Fig. 4 Experimental ECD spectrum of 4 in acetonitrile (black solid line) compared with the Boltzmann-weighted BH\&HLYP/TZVP spectrum (blue dashed curve) calculated for the B3LYP/6-31G(d) conformers of $(13 S, 14 R)-4$ in vacuo. Bars represent rotational strength values for the lowest-energy conformer.

The B97D/TZVP (PCM/MeCN) reoptimization of the initial conformers increased the population of the $13-\mathrm{OH}_{\mathrm{eq}}, 14-\mathrm{Me}_{\mathrm{eq}}$ conformer $(12.7 \%$ population represented by two conformers) and additional conformers $(22.0 \%$ population from three conformers) were also obtained, in which the $13-\mathrm{OH}$ is hydrogen-bonded to the $\mathrm{C}-16$ carbonyl group, while the 13- $\mathrm{OH}_{\mathrm{ax}}, 14-\mathrm{Me}_{\mathrm{ax}}$ conformer with 13-OH-C-8 carbonyl hydrogen bonding was still the major one with $53.0 \%$ population (Fig. S1, see ESI $\dagger$ ). The Boltzmann-weighted TDDFT-ECD spectra computed for the B97D/TZVP (PCM/MeCN) conformers did not improve the agreement with the experimental ECD spectrum any more (Fig. S2, see ESI $\dagger$ ). In order to correlate the ECD measurement in acetonitrile and the conformational analysis with PCM for acetonitrile, ${ }^{1} \mathrm{H}$ NMR was also recorded in acetonitrile- $d_{3}$ and $9.3 \mathrm{~Hz}{ }^{3} J_{13,14}$ coupling constant was measured in the decoupling experiment with the irradiation of $\mathrm{H}-17$ (Fig. S43, see ESI $\dagger$ ). This value indicated that the population of the $13-\mathrm{OH}_{\mathrm{eq}}, 14-\mathrm{Me}_{\mathrm{eq}}$ conformer was also underestimated by the B97D/TZVP (PCM/MeCN), which was supported by the fact that the computed ECD of the $13-\mathrm{OH}_{\mathrm{eq}}, 14-\mathrm{Me}_{\mathrm{eq}}$ conformers reproduced better the experimental ECD curve and the $306 \mathrm{~nm}$ negative CE derived only from these conformers.

The TDDFT-ECD and conformational analysis of the flexible RAL $_{12}$ derivatives $\mathbf{1}, \mathbf{3}$, and $\mathbf{4}$ with different substitution pattern on the macrolactone moiety revealed that although the similar ECD pattern of these related molecules derives from different conformational contributions, the negative/positive/positive/ negative/positive pattern of the CEs from the higher wavelength was preserved as long as the $(14 R)$ absolute configuration remained the same. The additional stereogenic centre at C-10 or C-13 could change the preferred conformation of the macrolide but it did not influence significantly the solution ECD spectra. Thus in contrast to the simple comparison of specific rotation values, the ECD spectra can serve as a good tool to identify whether an analogous $\mathrm{RAL}_{12}$ derivatives belong to the $(14 R)$ or $(14 S)$ series.

Compound 5 was obtained as colorless crystals $(\mathrm{MeOH})$ with a molecular formula of $\mathrm{C}_{16} \mathrm{H}_{20} \mathrm{O}_{6}$, as established by the HRESIMS analysis. The ${ }^{1} \mathrm{H}$ and ${ }^{13} \mathrm{C}$ NMR data (Tables 1 and 2) indicated the presence of two meta-coupled aromatic protons at $\delta_{\mathrm{H}} 6.05(\mathrm{H}-5)$ and $6.11(\mathrm{H}-3)$ ascribing from a tetrasubstituted benzene ring, five methylene protons at $\delta_{\mathrm{H}} 1.10-3.66(\mathrm{H}-7, \mathrm{H}-9$, and $\mathrm{H}-11$ to $\mathrm{H}-13)$, two oxygen-substituted methine groups at $\delta_{\mathrm{H}}$ $3.38(\mathrm{H}-10)$ and $3.66(\mathrm{H}-14)$, and a methyl group at $\delta_{\mathrm{H}} 1.05(\mathrm{H}-$ $17)$. Moreover, resonances for one ester carbonyl $\left(\delta_{\mathrm{C}} 171.5\right.$, C$16)$, one oxygenated quaternary carbon $\left(\delta_{\mathrm{C}} 101.0, \mathrm{C}-8\right)$, and four aromatic quaternary carbons $\left(\delta_{\mathrm{C}} 105.6-164.6, \mathrm{C}-1, \mathrm{C}-2, \mathrm{C}-4\right.$, and $\mathrm{C}-6)$ were detected. From the COSY data, a spin system containing $\mathrm{CH}_{2} \mathrm{CH}(\mathrm{O}) \mathrm{CH}_{2} \mathrm{CH}_{2} \mathrm{CH}_{2} \mathrm{CH}(\mathrm{O}) \mathrm{CH}_{3}$ fragment was identified (Fig. 2). The location of the above fragment was confirmed by the HMBC correlation from $\mathrm{H}-9$ to $\mathrm{C}-7$ and C-8 (Fig. 2). The NOE correlation observed between the axial methine protons $\mathrm{H}-10$ and $\mathrm{H}-14$ corroborated the cis orientation of the C-10 and C-14 substituents. Single crystal X-ray analysis of 5 , performed by using $\mathrm{Cu} \mathrm{K} \alpha$ radiation, confirmed these conclusions. The refined Flack parameter 0.1(3) allowed the assignment of the absolute configuration as $(8 R, 10 R, 14 R)$.

Compound 5 contains a chiral dihydroisocoumarin chromophore, for which an ECD helicity rule was introduced to correlate the $P / M$ helicity of the heteroring with positive/ negative $\mathrm{n}-\pi^{*} \mathrm{CE}$ and hence determine the absolute configuration of substituted dihydroisocoumarin derivatives. ${ }^{27}$ This helicity rule was confirmed by TDDFT-ECD calculations and applied to the configurational assignment of several natural dihydroisocoumarins. ${ }^{28,29}$ The ECD spectrum of 5 in acetonitrile showed a weak negative $\mathrm{CE}$ at $301 \mathrm{~nm}\left(\pi-\pi^{*}\right.$ transition) and a positive one at $269 \mathrm{~nm}\left(\mathrm{n}-\pi^{*}\right.$ transition), the latter of which suggested that the major solution conformer had $P$ helicity of the fused heteroring. This was in accordance with the solid- 
state X-ray geometry, in which the heteroring had envelop conformation with $\omega_{\mathrm{C}-6, \mathrm{C}-7, \mathrm{C}-8, \mathrm{O}}=+51.2^{\circ}$ torsional angle ( $P$ helicity) and the axial 8-OH group was hydrogen-bonded to the oxygen atom of the tetrahydro- $2 H$-pyran ring. In solution, the $P$ helicity conformer is in equilibrium with the $M$ helicity form, in which the 8-OH is equatorial (Fig. $5 \mathrm{c}$ ). This equilibrium clearly favors the $P$ helicity form having axial $8-\mathrm{OH}$, which was also observed for other 3-hydroxy-3,3-disubstituted dihydrocoumarin derivatives. ${ }^{28}$ The $P$ helicity of the heteroring and the axial orientation of the $8-\mathrm{OH}$ implies $(8 R)$ absolute configuration, while the $\mathrm{C}-14$ stereogenic centre of $\mathbf{5}$ corresponds to the $(14 R)$ stereogenic centre of $\mathbf{1 - 4}$, the absolute configuration of which must have preserved during the formation of the tetrahydro- $2 H$-pyran ring by an intramolecular oxa-Micheal addition from the biosynthetic precursor (vide infra). The structure of 5 was thus elucidated and it was named as brocapyrone A.

Compounds 6 and 7 had the same molecular formula, $\mathrm{C}_{15} \mathrm{H}_{20} \mathrm{O}_{4}$, as established by the HRESIMS data. Their ${ }^{1} \mathrm{H}$ NMR spectrum (Table 1) showed typical signals due to a 1,3,5trisubstituted benzene ring. Comparison of the ${ }^{1} \mathrm{H}-$ and ${ }^{13} \mathrm{C}-\mathrm{NMR}$ spectroscopic data with that of brocapyrone A (5) suggested that compounds 6 and 7 had similar framework as that of 5. The significant difference was identified as the ester carbonyl in $5\left(\delta_{\mathrm{C}} 171.5, \mathrm{C}-16\right)$ was replaced by a ketone carbonyl in $6\left(\delta_{\mathrm{C}} 208.2, \mathrm{C}-8\right)$ and $7\left(\delta_{\mathrm{C}} 204.9, \mathrm{C}-8\right)$. 2D NMR data confirmed this deduction (Fig. 2). Most of the ${ }^{1} \mathrm{H}$ - and ${ }^{13} \mathrm{C}-\mathrm{NMR}$ spectral data of 6 and 7 were very similar, except for those of $\mathrm{CH}-10$ and $\mathrm{CH}-14$, which implied that compounds 6 and 7 were diastereomers at C-10 or C-14. The geometry at C-10 and C-14 of 6 was deduced as cis on the basis of the observed NOE correlation between $\mathrm{H}-10$ and $\mathrm{H}-14$, while that of compound 7 was determined as trans according to the NOE correlation between $\mathrm{H}-10$ and $\mathrm{H}-16$. This assignment is in accordance with the NMR data of a related cis-tetrahydropyran oxa-Michael metabolite reported by Molnár and co-workers. ${ }^{30}$ Since the C-14 stereogenic centre of 6 and 7 must be homochiral with the $(14 R)$ stereogenic centre of 1-4 and $(14 R)$ of 5 , they should have $(10 R, 14 R)$ and $(10 S, 14 R)$ absolute configuration, respectively. The epimeric C-10 stereogenic centre of 6 and 7 was likely formed in the nonstereoselective intramolecular oxa-Michael cyclization of the $\alpha, \beta$-unsaturated ketone precursor. Thus the structures of

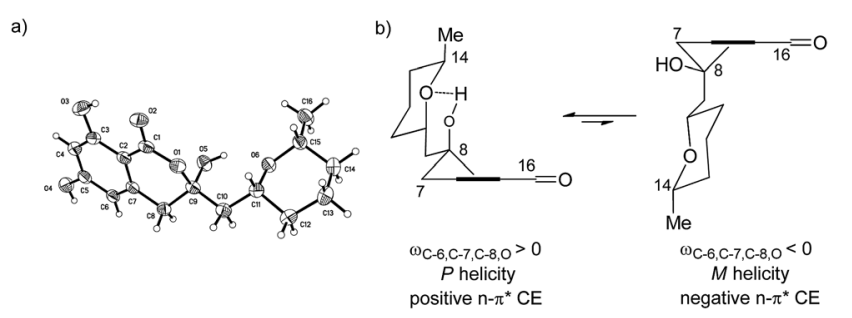

Fig. 5 (a) X-ray structure of 5 (note: a different numbering system is used for the structure in the text). (b) Equilibrating $P$ and $M$ helicity of the dihydroisocoumarin chromophore in $(8 R, 10 R, 14 R)-5$ as viewed from the direction of the benzene ring and helicity rule of the dihydroisocoumarin chromophore correlating the sign of the $n-\pi^{*}$ CE with the helicity of the heteroring. compounds 6 and 7 were determined and the trivial names brocaketones A and B were assigned to them, respectively.

Compound 8 was isolated as colorless oil with the molecular formula $\mathrm{C}_{15} \mathrm{H}_{20} \mathrm{O}_{4}$, same as that of 6 and 7, as deduced from the HRESIMS data. The ${ }^{1} \mathrm{H}$ NMR spectrum of 8 also showed signals for a 1,3,5-trisubstituted aromatic ring as well as for a methyl and several methylene groups. The ${ }^{13} \mathrm{C}$ NMR spectrum gave signals for 15 carbon atoms, corresponding to one methyl group, six aliphatic methylenes, three aromatic methines, three quaternary aromatic, and two ketocarbonyl carbons. The COSY spectrum revealed the presence of a spin system with a straight chain consisting of five methylene groups (C-9 to C-13, Fig. 2). This chain was terminated by two keto groups C-8 and C-14, as evidenced by the HMBC correlations from H-9 to C-8 and from $\mathrm{H}-13$ to C-14 (Fig. 2), respectively. The location of the remaining methylene at lower field $\left(\mathrm{C}-7, \delta_{\mathrm{C}} 50.2\right)$ was confirmed by the HMBC correlations of $\mathrm{H}-1$ and $\mathrm{H}-5$ with $\mathrm{C}-7$. Moreover, the HMBC correlations of $\mathrm{H}-7$ with $\mathrm{C}-8$ as well as $\mathrm{H}-15$ with $\mathrm{C}-14$ led to the determination of the structure of compound $\mathbf{8}$, which was named as brocaketone $\mathrm{C}$.

Compound 9 was isolated as colorless oil. The HRESIMS spectrum determined its molecular formula to be $\mathrm{C}_{15} \mathrm{H}_{22} \mathrm{O}_{4}$, with two hydrogen atoms more than that of 8 . The NMR data were very similar to those of compound $\mathbf{8}$, and the only difference was identified as the replacement of one of the two ketone carbonyl carbons at C-14 $\left(\delta_{\mathrm{C}} 210.9\right)$ of 8 by an oxygenated methine $\left(\delta_{\mathrm{C}} 66.2, \mathrm{C}-14\right)$ in $\mathbf{9}$. The structure was confirmed by further analysis of the HMBC and COSY correlations. The absolute configuration of $\mathrm{C}-14$ was tentatively assigned as $(R)$ on the basis of common biosynthetic origin with compounds 1-7. Compound 9 was named brocaketone D.

The isolation of compounds 1-9 provides further insight into the biosynthesis of 1,3-benzenediol derivatives. The domains of the nonreducing polyketide synthase (nrPKS) govern the formation of the resorcyclic acid unit of intermediate $\mathbf{B}$ from the linear polyketide intermediate $\mathbf{A}$ by aldol condensation and

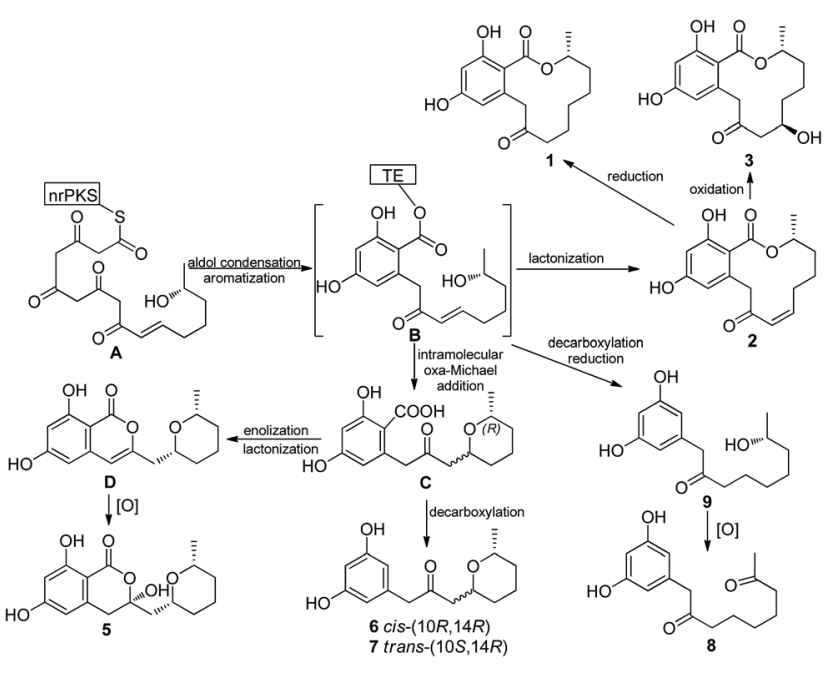

Scheme 1 Proposed biosynthetic scheme for the formation of RAL 12 (1-3) and other related 1,3-benzenediol derivatives (5-9). nrPKS: nonreducing polyketide synthase, TE: thioesterase. 
aromatization (Scheme 1). ${ }^{19}$ The thioesterase (TE) domain is responsible for the release of the $\mathrm{RAL}_{12}$ unit by a cyclization to a macrolactone ring $(\mathbf{B} \rightarrow 2)$, in which the conjugating double can be reduced or hydroxylated to afford 1 and 2, respectively. The dihydroisocoumarin derivative $\mathbf{5}$ forms in two cyclization steps followed by an oxidation; the intramolecular nondiastereoselective oxa-Michael addition of the sec-hydroxyl group to the $\beta$ carbon of the $\alpha, \beta$-unsaturated ketone produces a tetrahydropyran ring $(\mathbf{B} \rightarrow \mathbf{C})$, while the attack of the enolate oxygen to the carboxyl group forms the isocoumarin ring $(\mathbf{C} \rightarrow \mathbf{D})$. Intermediates $\mathbf{C}$ and $\mathbf{D}$ were reported earlier as hybrid metabolite in the programmed biosynthesis of fungal polyketides. $^{30}$ The epimeric $\mathbf{6}$ and 7 derivatives are obtained by the decarboxylation of intermediate C. Natural products 8 and $\mathbf{9}$ proves the involvement of the acyclic 1,3-benzenediol intermediate $\mathbf{B}$, the decarboxylation and reduction of which do not allow cyclization of the side chain (Scheme 1).

The isolated compounds 1-9 were evaluated for their DPPH and ABTS radical scavenging capacities. Compounds 3, 6, and 7 showed comparable DPPH radical scavenging activity $\left(\mathrm{IC}_{50}\right.$ values of $14.4,5.9$, and $16.3 \mu \mathrm{g} \mathrm{mL} \mathrm{m}^{-1}$ ) to that of BHT, a well-known antioxidant $\left(\mathrm{IC}_{50}=18.5 \mu \mathrm{g} \mathrm{mL} \mathrm{m}^{-1}\right)$. The activity of compound 6 is three-fold better than that of 7 , suggesting that the configuration at $\mathrm{C}-10$ has an effect on the DPPH radical scavenging activity. Furthermore, compound $\mathbf{3}$ displayed much higher activity than compounds 1 and $4\left(\mathrm{IC}_{50}>150 \mu \mathrm{g} \mathrm{mL}{ }^{-1}\right)$, implying that the additional hydroxy group and its position in the macrolactone ring also influences the activity. Compounds 6, 7, and 9 showed moderate inhibitory activity toward ABTS radicals with $\mathrm{IC}_{50}$ values of $8.7,18.7$, and $15.6 \mu \mathrm{g} \mathrm{mL}{ }^{-1}$, respectively, comparable to that of ascorbic acid $\left(\mathrm{IC}_{50}=11.9 \mu \mathrm{g} \mathrm{mL}{ }^{-1}\right)$. Compound 6 again showed better activity than that of 7 , which confirmed that the configuration at $\mathrm{C}-10$ affected the antioxidant activity.

\section{Conclusions}

In conclusion, six new secondary metabolites including a new resorcylic acid derivative 13-hydroxydihydroresorcylide (4), and five new loop-opened resorcylic acid-related congeners including brocapyrone A (5) and brocaketones A-D (6-9), were isolated and identified from the marine-derived endophytic fungus $P$. brocae MA-192. The $14 R$ absolute configuration of 1, 3, and 4 were confirmed by conformational analysis and TDDFTECD calculations. The single crystal X-ray data of compounds 3 and $\mathbf{5}$ allowed applying the solid-state TDDFT-ECD approach for 3 to compare the structures of solution and solid-state conformers and correlate the $n-\pi^{*}$ ECD transition of 5 with the helicity and absolute configuration of the dihydroisocoumarin moiety. Compounds 3, 6, and 7 showed scavenging activity against DPPH radicals, while compounds 6, 7, and 9 showed activity against ABTS radicals.

\section{Experimental section}

\section{General experimental procedures}

Optical rotations were determined on an Optical Activity AA-55 polarimeter. Ultraviolet (UV) spectra were recorded on a
Lengguang Gold Spectrumlab-54 spectrophotometer, $\lambda_{\max }$ in $\mathrm{nm}$. ECD spectra were acquired on a J-810 spectropolarimeter. The ${ }^{1} \mathrm{H}-,{ }^{13} \mathrm{C}-$, and 2D NMR spectra were obtained on Bruker Avance 500 spectrometer ( $500 \mathrm{MHz}$ for ${ }^{1} \mathrm{H}$ and $125 \mathrm{MHz}$ for ${ }^{13} \mathrm{C}$ ), $\delta$ in ppm with TMS as internal standard, $J$ in Hz. Low and high ESIMS were obtained on a VG Auto spec 3000 spectrometer, in $m / z$. HPLC were performed on a Dionex HPLC system with a P680 pump, an ASI100 automated sample injector, a TCC-100 column oven, a UVD 340U multiple wavelength detector, and a Dionex Acclaim ODS column $(4.6 \times 250 \mathrm{~mm}, 5 \mu \mathrm{m})$. Prep. HPLC were taken on a Dionex UltiMate U3000 system using an Agilent Prep RP-18 column $(21 \times 250 \mathrm{~mm}, 10 \mu \mathrm{m})$ with UV detection. Silica gel ( $\mathrm{SiO}_{2}$; 100-200 mesh, 200-300 mesh, and $\mathrm{GF}_{254}$, Qingdao Haiyang Chemical Group Corporation, China), RP-18 reverse-phase silica gel (40-63 $\mu \mathrm{m}$, Merck, Darmstadt), and Sephadex LH-20 (Merck, Darmstadt) were used for open column chromatography.

\section{Fungal material}

The endophytic fungal strain P. brocae MA-192 was isolated from fresh leaves of the marine mangrove plant Avicennia marina, which was collected from Hainan Island, P. R. China, in August 2012. The fungus was identified based on its ITS region of the rDNA and the sequence was deposited at GenBank, with accession number KF513181. A BLAST search result showed that the sequence was the most similar (99\%) to the sequence of Penicillium brocae (compared to no. AF484394). The strain was preserved at the Institute of Oceanology, Chinese Academy of Sciences.

\section{Cultivation}

For chemical investigations, the fungal strain was statically fermented at r.t. for 30 days on PDB medium (2\% mannitol, $1 \%$ glucose, $0.3 \%$ peptone, $0.5 \%$ yeast extract, and seawater $300 \mathrm{~mL}$ per flask, pH 6.5-7.0) in $1000 \mathrm{~mL}$ Fernbach flasks $(\times 60)$.

\section{Extraction and isolation}

The fermented culture was filtered to separate the culture broth and mycelia. The former was extracted three times with EtOAc, while the latter was extracted with a mixture of $80 \%$ acetone in $\mathrm{H}_{2} \mathrm{O}$. The acetone solution was evaporated to afford an aqueous solution, which was then exhaustively extracted with EtOAc. Since the two EtOAc extracts showed identical HPLC and TLC profiles, they were combined and concentrated to afford a crude extract $(28.0 \mathrm{~g})$, which was fractionated by silica gel vacuum liquid chromatography (VLC) using different solvents of increasing polarity from petroleum ether (PE) to $\mathrm{MeOH}$, to yield eight fractions (Frs 1-8), based on TLC analysis. Fr. 4 (2.0 g) was separated by column chromatography (CC) on Lobar LiChroprep $\mathrm{C}_{18}$ eluting with $\mathrm{MeOH}-\mathrm{H}_{2} \mathrm{O}$ gradient to give seven subfractions (Frs 4.1-4.7). Further purification of Fr. 4.3 by CC on silica gel with a $\mathrm{CHCl}_{3}-\mathrm{MeOH}$ gradient (from $0: 1$ to $10: 1$ ), Sephadex LH-20 (MeOH) and prep. HPLC $\left(60 \% \mathrm{MeOH} / \mathrm{H}_{2} \mathrm{O}\right)$ yielded compounds 1 (42.5 mg, $\left.t_{\mathrm{R}} 32.0 \mathrm{~min}\right), 5\left(9.7 \mathrm{mg}, t_{\mathrm{R}}\right.$ $30.4 \mathrm{~min})$, and 6 ( $\left.28.7 \mathrm{mg}, t_{\mathrm{R}} 26.9 \mathrm{~min}\right)$. Fr. 4.6 was subjected to Sephadex LH-20 (MeOH) and preparative-TLC to afford compounds 2 (9.6 mg) and 7 (9.6 mg). Fr. 5 (3.4 g) was chromatographed over silica gel $\left(\mathrm{CHCl}_{3} / \mathrm{MeOH}, 40: 1-10: 1\right)$ and 
Sephadex LH-20 $(\mathrm{MeOH})$ to give compounds $3(8.7 \mathrm{mg}), 4$ (5.0 $\mathrm{mg}), 8$ (4.5 mg), and 9 (46.0 mg).

$(\boldsymbol{R})$-Dihydroresorcylide (1). White amorphous powder; $[\alpha]_{\mathrm{D}}^{20}$ +37 (c 0.13, MeOH). ECD (MeCN, $\lambda[\mathrm{nm}](\Delta \varepsilon), c=2.28 \times 10^{-3}$ M): 307 (-0.62), 285sh (0.68), 260 (5.49), 227 (2.90), 212 (-8.84), positive below $194 \mathrm{~nm} .{ }^{1} \mathrm{H}$ - and ${ }^{13} \mathrm{C}-\mathrm{NMR}$ data are in accordance with that of reported. ${ }^{19}$

$(\boldsymbol{R})$-cis-Resorcylide (2). White amorphous powder; $[\alpha]_{\mathrm{D}}^{20}-40$ (c $0.1, \mathrm{MeOH}) .{ }^{1} \mathrm{H}$ - and ${ }^{13} \mathrm{C}-\mathrm{NMR}$ data are in accordance with that of reported. ${ }^{19}$

(10R,14R)-10-Hydroxydihydroresorcylide (3). White amorphous powder; $[\alpha]_{\mathrm{D}}^{20}-14(c 0.2, \mathrm{MeOH})$. ECD $(\mathrm{MeCN}, \lambda[\mathrm{nm}]$ $\left.(\Delta \varepsilon), c=2.27 \times 10^{-3} \mathrm{M}\right): 306(-1.20), 290(-0.52), 260$ (5.33), 229 (1.61), 212 (-5.79), positive below $197 \mathrm{~nm}$. ECD $52 \mu \mathrm{g} 3 \mathrm{in}$ $245 \mathrm{mg} \mathrm{KCl}, \lambda_{\max }[\mathrm{nm}](\phi): 306(-9.70), 285 \mathrm{sh}(-4.97), 258$ (7.76), 236 (4.46), 215 (-5.35). ${ }^{1} \mathrm{H}$ - and ${ }^{13} \mathrm{C}-\mathrm{NMR}$ data are in accordance with that of reported. ${ }^{19}$

13-Hydroxydihydroresorcylide (4). White amorphous powder; $[\alpha]_{\mathrm{D}}^{20}-17(c 0.2, \mathrm{MeOH})$. UV $(\mathrm{MeOH}) \lambda_{\max }(\log \varepsilon): 212$ (4.05), 263 (3.76), 302 (3.49) nm. ECD (MeCN, $\lambda[\mathrm{nm}](\Delta \varepsilon), c=$ $\left.6.50 \times 10^{-4} \mathrm{M}\right): 306$ (-0.53), 284sh (0.35), 263 (3.75), 229 (1.70), $213(-5.02)$, positive below 198. ${ }^{1} \mathrm{H}$ - and ${ }^{13} \mathrm{C}-\mathrm{NMR}$ : see Tables 1 and 2. ESIMS (positive): $m / z 331[\mathrm{M}+\mathrm{Na}]^{+}$. HRESIMS (positive): $m / z 331.1150\left([\mathrm{M}+\mathrm{Na}]^{+}\right.$, calcd for $\left.\mathrm{C}_{16} \mathrm{H}_{20} \mathrm{O}_{6} \mathrm{Na} 331.1152\right)$.

Brocapyrone A (5). Colorless crystals (MeOH); m.p. 166-168 ${ }^{\circ} \mathrm{C} .[\alpha]_{\mathrm{D}}^{20}-21(c 0.2, \mathrm{MeOH}) . \mathrm{UV}(\mathrm{MeOH}) \lambda_{\max }(\log \varepsilon): 214$ (4.18), 266 (3.92), 301 (3.60) nm. ECD (MeCN, $\lambda[\mathrm{nm}](\Delta \varepsilon), c=9.19 \times$ $\left.10^{-4} \mathrm{M}\right): 301$ (-0.10), 292sh (-0.08), 269 (0.23), 245 (-0.04), 235 (0.07), 222 (-0.21), 209sh (0.14), 196 (0.68). ${ }^{1} \mathrm{H}-$ and ${ }^{13} \mathrm{C}-\mathrm{NMR}$ : see Tables 1 and 2. ESIMS (positive): $m / z 309[\mathrm{M}+\mathrm{H}]^{+}$. HRESIMS (positive): $m / z 309.1331\left([\mathrm{M}+\mathrm{H}]^{+}\right.$, calcd for $\mathrm{C}_{16} \mathrm{H}_{21} \mathrm{O}_{6}$ 309.1333).

Brocaketone A (6). Colorless oil; $[\alpha]_{\mathrm{D}}^{20}-27$ (c 0.1, MeOH). UV $(\mathrm{MeOH}) \lambda_{\max }(\log \varepsilon): 202$ (4.22), 281 (3.04) nm. ECD (MeCN, $\lambda$ $\left.[\mathrm{nm}](\Delta \varepsilon), c=9.47 \times 10^{-4} \mathrm{M}\right): 303(-0.08), 231(0.15), 222$ $(-0.25), 204(-0.80), 198(0.78) .{ }^{1} \mathrm{H}-$ and ${ }^{13} \mathrm{C}-\mathrm{NMR}$ : see Tables 1 and 2. ESIMS (positive): $m / z 287[\mathrm{M}+\mathrm{Na}]^{+}$. HRESIMS (positive): $m / z 287.1262\left([\mathrm{M}+\mathrm{Na}]^{+}\right.$, calcd for $\left.\mathrm{C}_{15} \mathrm{H}_{20} \mathrm{O}_{4} \mathrm{Na} 287.1254\right)$.

Brocaketone $\mathbf{B}(7)$. White amorphous powder; $[\alpha]_{\mathrm{D}}^{20}-30$ (c 0.1, MeOH). UV (MeOH) $\lambda_{\max }(\log \varepsilon): 202(4.43), 282(3.33) \mathrm{nm}$. $\operatorname{ECD}\left(\mathrm{MeCN}, \lambda[\mathrm{nm}](\Delta \varepsilon), c=1.26 \times 10^{-3} \mathrm{M}\right): 300(-0.06), 231$ (0.07), 203 (-0.63), 196 (0.73). ${ }^{1} \mathrm{H}$ - and ${ }^{13} \mathrm{C}-\mathrm{NMR}$ : see Tables 1 and 2. ESIMS (positive): $m / z 265[\mathrm{M}+\mathrm{H}]^{+}$. HRESIMS (positive): $m / z 265.1433\left([\mathrm{M}+\mathrm{H}]^{+}\right.$, calcd for $\left.\mathrm{C}_{15} \mathrm{H}_{21} \mathrm{O}_{4} 265.1434\right)$.

Brocaketone C (8). Colorless oil; UV $(\mathrm{MeOH}) \lambda_{\max }(\log \varepsilon): 203$ (4.35), 281 (3.25) nm. ${ }^{1} \mathrm{H}-$ and ${ }^{13} \mathrm{C}-\mathrm{NMR}$ : see Tables 1 and 2. ESIMS (positive): $m / z 265[\mathbf{M}+\mathbf{H}]^{+}$. HRESIMS (positive): $m / z$ 265.1436 $\left([\mathrm{M}+\mathrm{H}]^{+}\right.$, calcd for $\mathrm{C}_{15} \mathrm{H}_{21} \mathrm{O}_{4}$ 265.1434).

Brocaketone D (9). Colorless oil; $[\alpha]_{\mathrm{D}}^{20}-8\left(c 0.3, \mathrm{CHCl}_{3}\right)$. UV $(\mathrm{MeOH}) \lambda_{\max }(\log \varepsilon): 203$ (4.54), $281(3.36) \mathrm{nm} .{ }^{1} \mathrm{H}$ - and ${ }^{13} \mathrm{C}-\mathrm{NMR}$ : see Tables 1 and 2. ESIMS (positive): $m / z 267[\mathrm{M}+\mathrm{H}]^{+}$. HRESIMS (positive): $m / z 267.1593\left([\mathrm{M}+\mathrm{H}]^{+}\right.$, calcd for $\mathrm{C}_{15} \mathrm{H}_{23} \mathrm{O}_{4} 267.1591$ ).

\section{Computational section}

Mixed torsional/low mode conformational searches were carried out by means of the Macromodel 9.9.223 (ref. 31) software using Merck Molecular Force Field (MMFF) with implicit solvent model for chloroform applying a $21 \mathrm{~kJ} \mathrm{~mol}^{-1}$ energy window. Geometry reoptimizations of the resultant conformers [B3LYP/6-31G(d) level in vacuo and B97D/TZVP with PCM solvent model for MeCN] and TDDFT calculations were performed with Gaussian 09 (ref. 32) using various functionals (B3LYP, BH\&HLYP, PBE0) and TZVP basis set. ECD spectra were generated as the sum of Gaussians ${ }^{33}$ with 2100 and $3000 \mathrm{~cm}^{-1}$ half-height width (corresponding to $c a .14$ and $20 \mathrm{~nm}$ at $260 \mathrm{~nm}$, respectively), using dipole-velocity computed rotational strengths. Boltzmann distributions were estimated from the ZPVE corrected B3LYP/6-31G(d) energies in the gas-phase calculations and from the B97D/TZVP energies in the PCM model ones. The MOLEKEL ${ }^{34}$ software package was used for visualization of the results.

\section{X-ray crystallographic analysis of compound 5}

Colorless prismatic crystals of $\mathbf{5}$ were obtained by recrystallization from $\mathrm{MeOH} . \mathrm{C}_{16} \mathrm{H}_{20} \mathrm{O}_{6}, M_{\mathrm{r}}=308.32$, monoclinic space group $P 2(1)$, unit cell dimensions $a=9.0904(11) \AA, b=$ 11.7580(14) ̊, $c=14.2487(16) \AA, V=1523.0(3) \AA^{3}, \alpha=\beta=\gamma=$ $90^{\circ}, Z=4, d_{\text {calcd }}=1.345 \mathrm{mg} \mathrm{m}^{-3}$, crystal dimensions $0.40 \times$ $0.30 \times 0.16 \mathrm{~mm}, \mu=0.860 \mathrm{~mm}^{-1}, F(000)=656$. The 3226 measurements yielded 2271 independent reflections after equivalent data were averaged, and Lorentz and polarization corrections were applied. The final refinement gave $R_{1}=0.0387$ and $w R_{2}=0.0891[I>2 \sigma(I)]$. The absolute structure parameter was $0.1(3)$. All crystallographic data ${ }^{35}$ were collected on a Bruker Smart-1000 CCD diffractometer equipped with graphitemonochromated $\mathrm{Cu} \mathrm{K} \alpha$ radiation $(\lambda=1.54178 \AA)$ at $293(2) \mathrm{K}$. The data were corrected for absorption by using the program SADABS. ${ }^{36}$ The structure was solved by direct methods with the SHELXTL software package. ${ }^{37}$ All non-hydrogen atoms were refined anisotropically. The $\mathrm{H}$ atoms were located by geometrical calculations, and their positions and thermal parameters were fixed during the structure refinement. The structure was refined by full-matrix least-squares techniques. ${ }^{38}$

\section{DPPH radical scavenging activity}

The scavenging activity against DPPH radicals were monitored according to the method of Sharma and Bhat ${ }^{39}$ with some modifications. Briefly, a $100 \mu \mathrm{L}$ aliquot of test sample (in methanol) was added $100 \mu \mathrm{L}$ of $0.16 \mathrm{mM}$ DPPH methanolic solution. The mixture was vortexed for $1 \mathrm{~min}$ and then left to stand at room temperature for $30 \mathrm{~min}$ in the dark, and its absorbance was read at $517 \mathrm{~nm}$. BHT was used as a positive reference.

\section{Trolox equivalent antioxidant capacity (TEAC)}

The ABTS cation radical scavenging activity was measured according to the method of Re et al. ${ }^{40}$ with some modification. The ABTS radical cation was produced by the reaction between $7.0 \mathrm{mM} \mathrm{ABTS} / \mathrm{H}_{2} \mathrm{O}$ with $\mathrm{MnO}_{2}$ powder. This solution was then diluted in $5 \mathrm{mM}$ PBS (pH 7.4) and adjusted to an absorbance of $0.700 \pm 0.02$ at $734 \mathrm{~nm}$. Compounds were diluted with $\mathrm{MeOH}$ to produce solutions of $5,10,25,50,100$, and $200 \mu \mathrm{g} \mathrm{mL}^{-1}$ 
concentration. The reaction was initiated by adding $60 \mu \mathrm{L}$ of sample solution to $240 \mu \mathrm{L}$ of ABTS radical solution. After 6 min of incubation at room temperature, the absorbance value of the mixture was measured at $734 \mathrm{~nm}$ in a UV/Vis spectrophotometer. Ascorbic acid was used as a positive control.

\section{Acknowledgements}

Financial support from the Natural Science Foundation of China (31270403 and 30910103914) and from the Ministry of Science and Technology of China (2010CB833802 and 2013AA092901) is gratefully acknowledged. T.K. and A.M. thank the Hungarian National Research Foundation (OTKA K105871) for financial support and the National Information Infrastructure Development Institute (NIIFI 10038) for computer time.

\section{Notes and references}

1 B. Halliwell, Biochem. J., 2007, 401, 1.

2 M. F. Katja, B. Volker, D. W. Anthony and M. K. Gabriele, J. Nat. Prod., 2003, 66, 968.

3 M. S. Bai, C. Wang, S. C. Zong, M. Lei and J. M. Gao, Food Chem., 2013, 141, 3424.

4 R. Olinski, D. Gackowski, M. Foksinski, R. Rozalski, K. Roszkowski and P. Jaruga, Free Radical Biol. Med., 2002, 33, 192.

5 E. Choe and D. B. Min, Compr. Rev. Food Sci. Food Saf., 2006, 5, 169.

6 R. Kahl and H. Z. Kappus, Z. Lebensm.-Unters. Forsch., 1993, 196, 329.

7 F. Caputo, R. Vegliante and L. Ghibelli, Biochem. Pharmacol., 2012, 84, 1292.

8 J. J. Han, L. Bao, L. W. He, X. Q. Zhang, X. L. Yang, S. J. Li, Y. J. Yao and H. W. Liu, J. Nat. Prod., 2013, 76, 1448.

9 S. B. Wu, S. M. Rachel, D. W. Bruce, L. Amy and J. K. Edward, J. Nat. Prod., 2012, 75, 2246.

10 R. Carolina, Z. Hanaa, M. Virginia and Z. Eva, J. Nat. Prod., 2013, 76, 621.

11 J. Sun, J. Yu, P. C. Zhang, F. Tang, Y. D. Yue, Y. N. Yang and Z. M. Feng, J. Agric. Food Chem., 2013, 61, 4556.

12 S. Z. Tian, X. Pu, G. Y. Luo, L. H. Xu, L. X. Zhao, L. H. Xu, W. J. Li and Y. G. Luo, J. Agric. Food Chem., 2013, 61, 3006.

13 J. W. Blunt, B. R. Copp, R. A. Keyzers, M. H. G. Munro and M. R. Prinsep, Nat. Prod. Rep., 2012, 29, 144.

14 Y. Zhang, X. M. Li, Z. Shang, C. S. Li, N. Y. Ji and B. G. Wang, J. Nat. Prod., 2012, 75, 1888.

15 C. S. Li, X. M. Li, S. S. Gao, Y. H. Lu and B. G. Wang, Mar. Drugs, 2013, 11, 3068.

16 C. Y. An, X. M. Li, H. Luo, C. S. Li, M. H. Wang, G. M. Xu and B. G. Wang, J. Nat. Prod., 2013, 76, 1896.

17 M. H. Wang, X. M. Li, C. S. Li, N. Y. Ji and B. G. Wang, Mar. Drugs, 2013, 11, 2230.
18 P. Zhang, L. H. Meng, A. Mándi, T. Kurtán, X. M. Li, Y. Liu, X. Li, C. S. Li and B. G. Wang, Eur. J. Org. Chem., 2014, 4029. 19 Y. Xu, T. Zhou, P. Espinosa-Artiles, Y. Tang, J. Zhan and I. Molnár, ACS Chem. Biol., 2014, 9, 1119.

20 S. M. Poling, D. T. Wicklow, K. D. Rogers and J. B. Gloer, J. Agric. Food Chem., 2008, 56, 3006.

21 C. J. Barrow, J. Nat. Prod., 1997, 60, 1023.

22 L. Zhang, W. Q. Ma, L. L. Xu, F. Deng and Y. W. Guo, Chin. J. Chem., 2013, 31, 339.

23 W. Ebrahim, A. H. Aly, A. Mándi, F. Totzke, M. H. G. Kubbutat, V. Wray, H. Dai, P. Proksch, T. Kurtán and A. Debbab, Eur. J. Org. Chem., 2012, 3476.

24 J. Dai, K. Krohn, U. Flörke, G. Pescitelli, G. Kerti, T. Papp, K. E. Kövér, A. C. Bényei, S. Draeger, B. Schulz and T. Kurtán, Eur. J. Org. Chem., 2010, 6928.

25 H. Hussain, K. Krohn, U. Flörke, B. Schulz, S. Draeger, G. Pescitelli, P. Salvadori, S. Antus and T. Kurtán, Tetrahedron: Asymmetry, 2007, 18, 925.

26 M. I. Kawada, T. Kawai, M. Goto, Y. J. Wang and Y. Kawakami, J. Chem. Inf. Model., 2009, 49, 2650.

27 G. Kerti, T. Kurtán, T. Z. Illyés, K. E. Kövér, S. Sólyom, G. Pescitelli, N. Fujioka, N. Berova and S. Antus, Eur. J. Org. Chem., 2007, 296.

28 W. Ebrahim, A. H. Aly, A. Mándi, V. Wray, E. M. Essassi, T. Ouchbani, R. Bouhfid, W. Lin, P. Proksch, T. Kurtán and A. Debbab, Chirality, 2013, 25, 250.

29 T. Kurtán, S. Antus and G. Pescitelli, Electronic CD of benzene and other aromatic chromophores for determination of absolute configuration in comprehensive chiroptical spectroscopy: applications in stereochemical analysis of synthetic compounds, natural products, and biomolecules, ed. $\mathrm{N}$. Berova, P. L. Polavarapu, K. Nakanishi and R. W. Woody, John Wiley, Hoboken, 2012, vol. 2, p. 73.

30 Y. Q. Xu, T. Zhou, S. W. Zhang, L. J. Xuan, J. X. Zhan and I. Molnár, J. Am. Chem. Soc., 2013, 135, 10783.

31 MacroModel, Schrödinger LLC, 2012, http://www. schrodinger.com/productpage/14/11/.

32 M. J. Frisch, G. W. Trucks and H. B. Schlegel, et al., Gaussian 09, revision B.01, Gaussian, Inc., Wallingford CT, 2010.

33 P. J. Stephens and N. Harada, Chirality, 2010, 22, 229.

34 U. Varetto, MOLEKEL, v. 5.4, Swiss National Supercomputing Centre, Manno, Switzerland, 2009.

$35 \mathrm{ESI}^{\dagger}$

36 G. M. Sheldrick, SADABS, University of Göttingen, Germany, 1996.

37 G. M. Sheldrick, SHELXTL, Bruker Analytical X-ray System Inc., Madison, WI, 1997.

38 G. M. Sheldrick, SHELXL-97 and SHELXS-97, University of Göttingen, Germany, 1997.

39 O. P. Sharma and T. K. Bhat, Food Chem., 2009, 113, 1202.

40 R. Re, N. Pellegrini, A. Proteggente, A. Pannala, M. Yang and C. Rice-Evans, Free Radical Biol. Med., 1999, 26, 1231. 